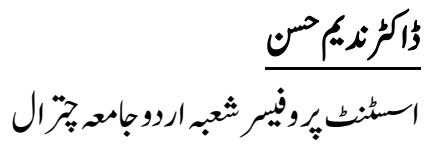

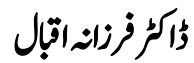

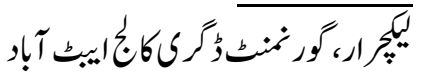

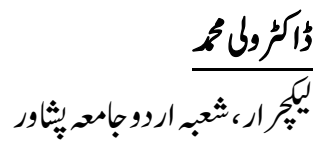

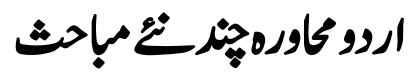

Dr Nadeem Hassan

Assistant professor, Department of Urdu, University of Chitral.

Dr. Farzana Iqbal

Lecturer, Govt Degree College Abbotabad.

Dr Wali Muhammad

Lecturer, Department of Urdu, University of Peshawar.

\section{Urdu Muhawara Chand Naey Mabahis}

Idioms are specifically important in any language of the world because they give us a new creative way to express our view and to speak fluently. Unfortunately the new learners of Urdu language don't know about the authentic definition of Idioms and its usage and meaning in their specific context. In this research paper the researchers have shed light on the nature, combination, types and usage of Urdu Proverbs.

Keywords: Idiom, definition, types, misconceptions, examples, analysis.

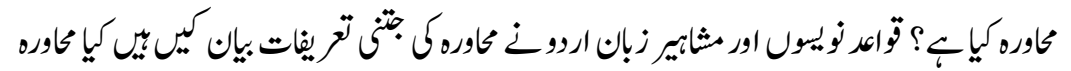

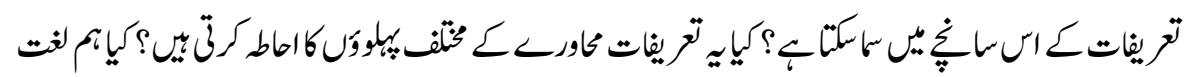

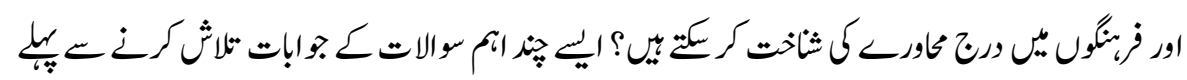

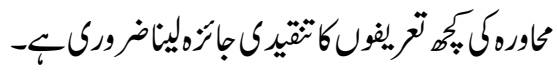

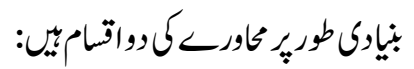




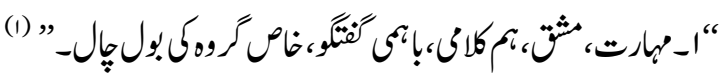

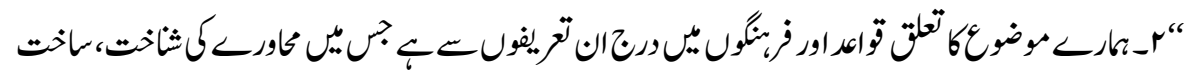

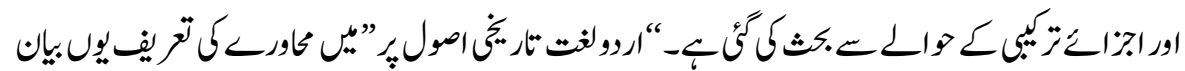

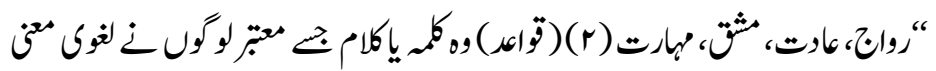

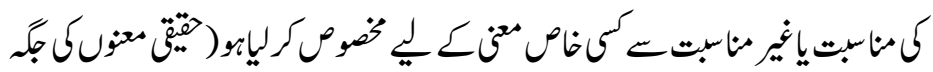

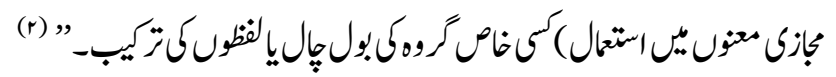

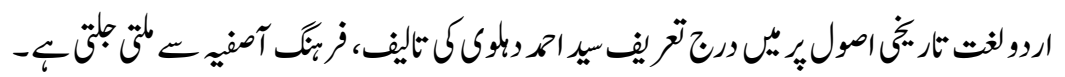

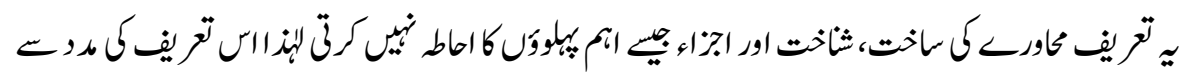

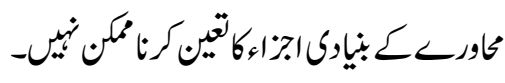

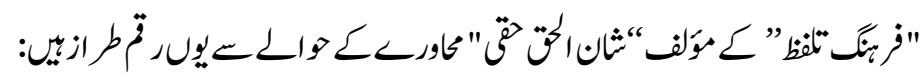

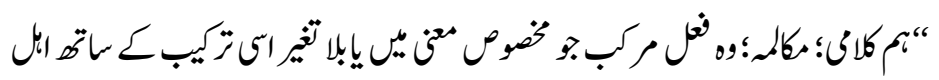

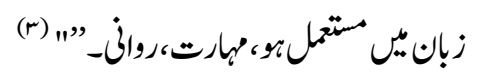

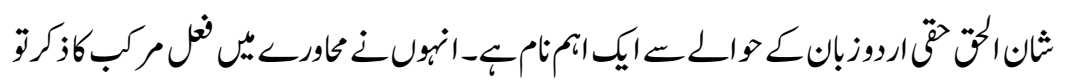

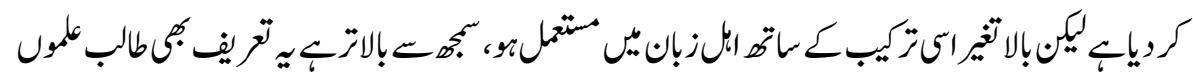

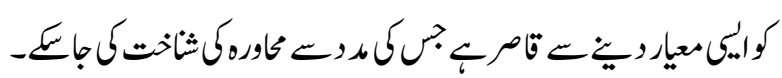

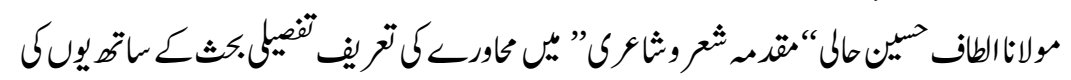

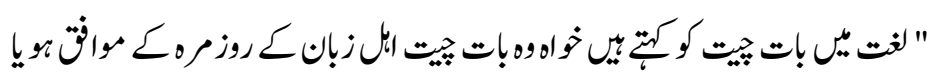

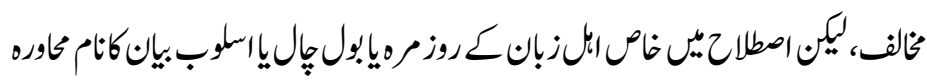

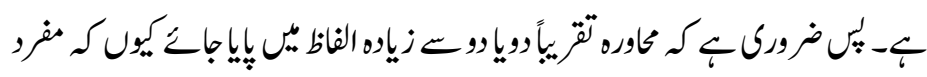

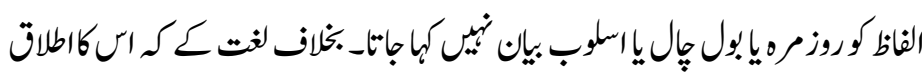

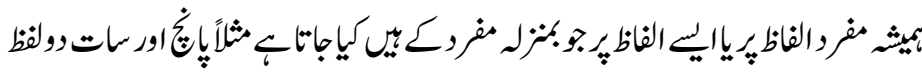




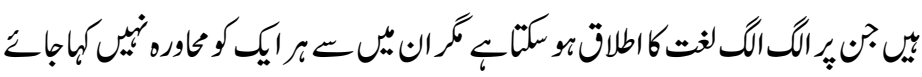

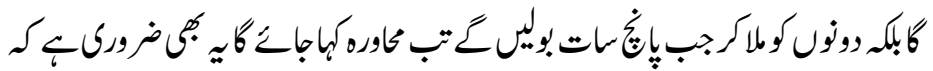

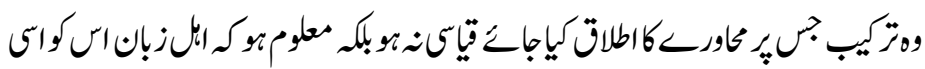

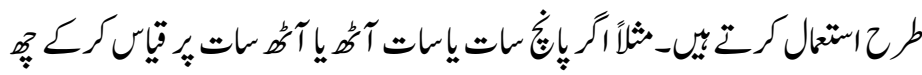

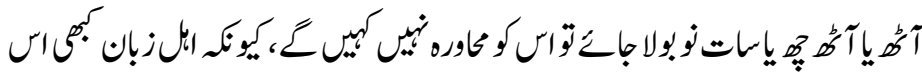

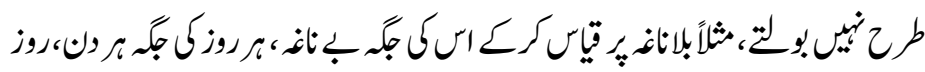

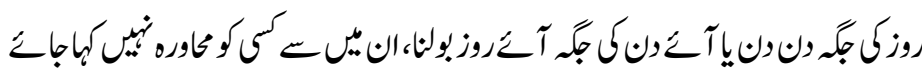

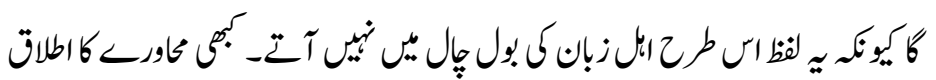

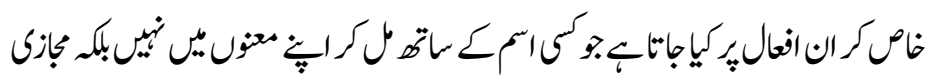

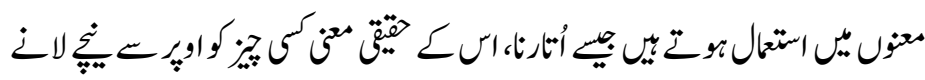

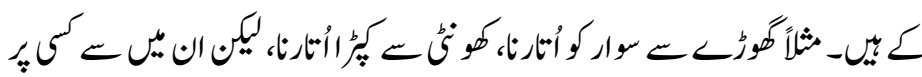

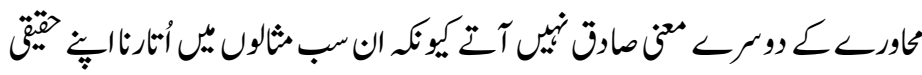

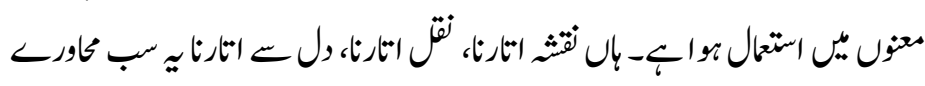

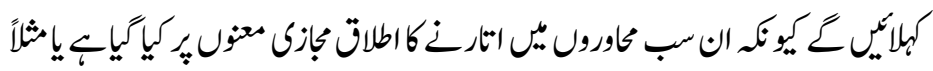

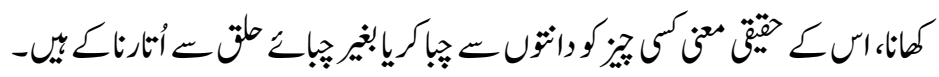

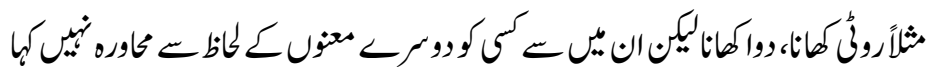

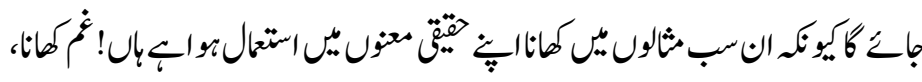

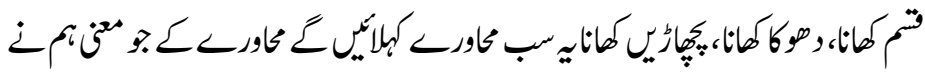

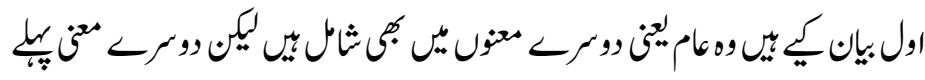

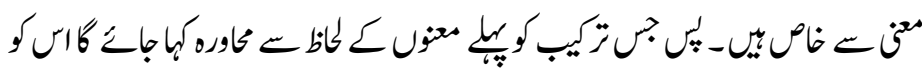

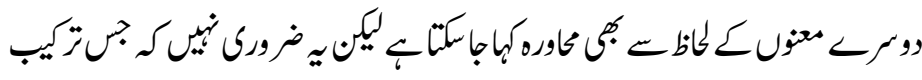

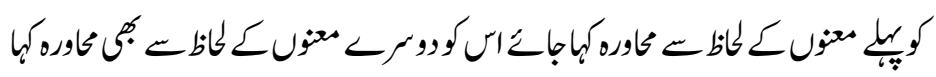

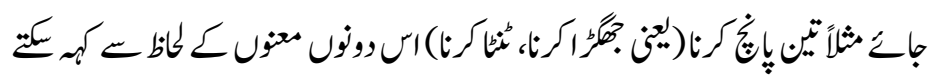




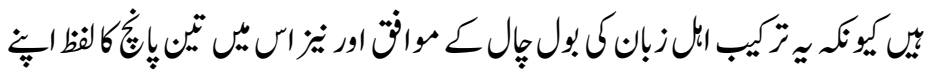

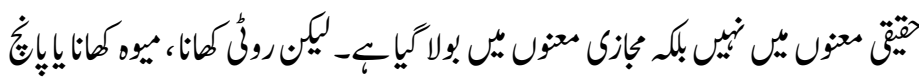

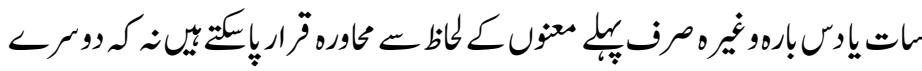

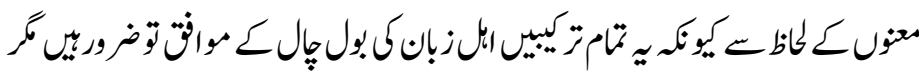

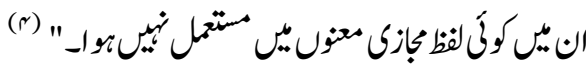

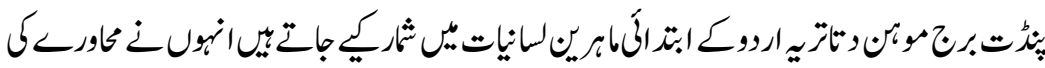
تريفيليبانككب

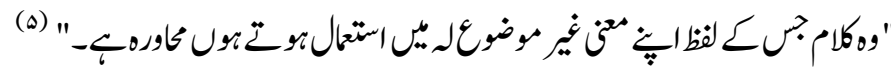

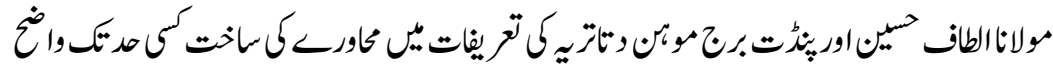

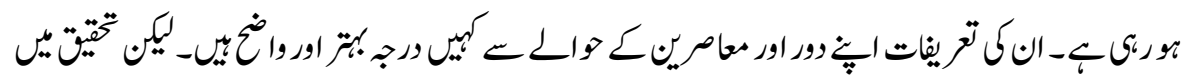

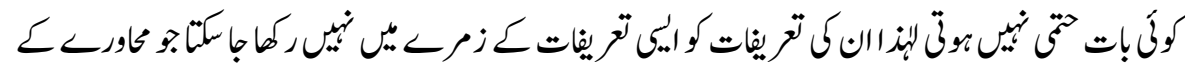

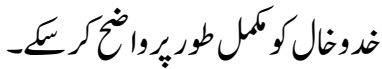

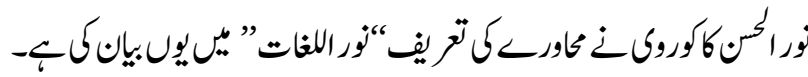

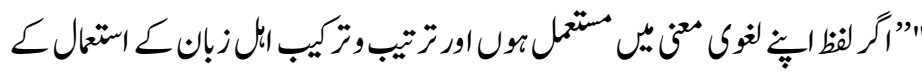

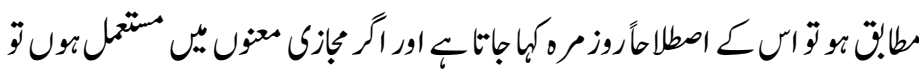

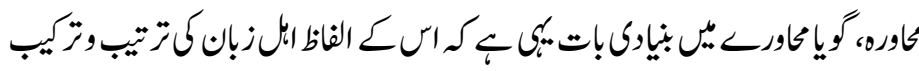

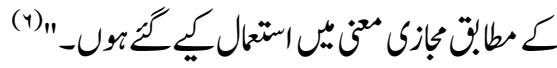

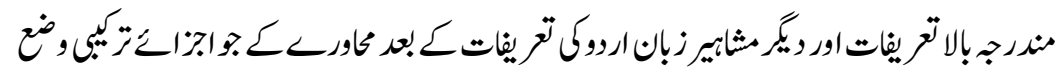

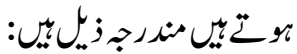
ا-

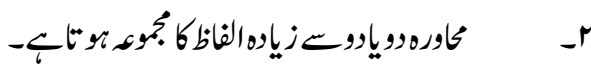

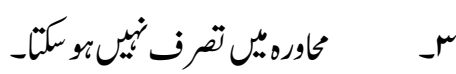

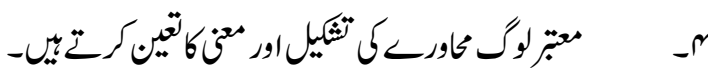


هـ - محاورهوبر

(L)

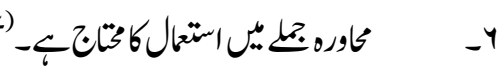

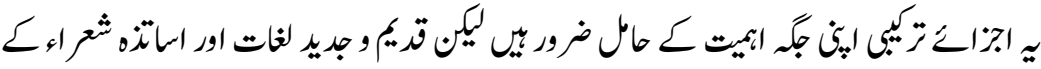

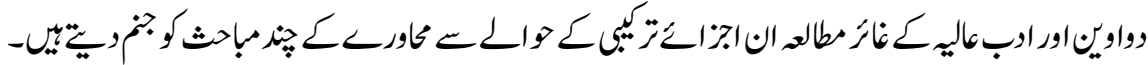

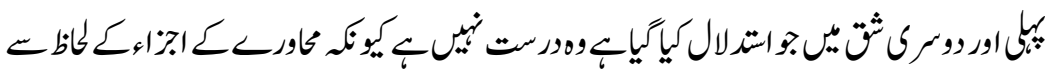

$$
\begin{aligned}
& \text { وواقامثيل- }
\end{aligned}
$$

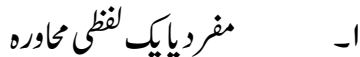

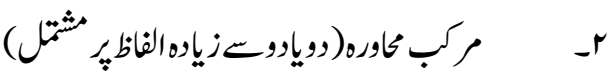

$$
\begin{aligned}
& \text { مغرويايك لفظى محاوره: }
\end{aligned}
$$

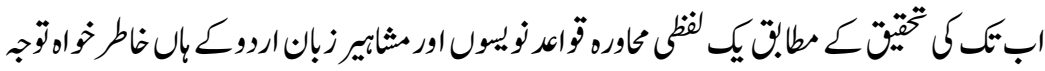

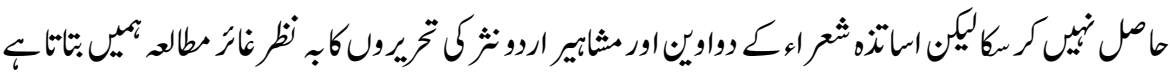

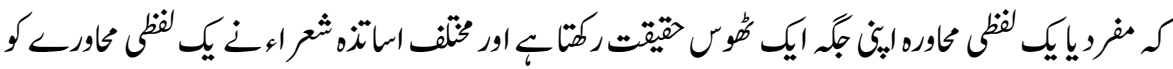

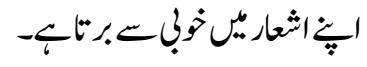

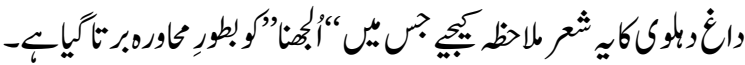

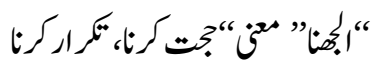

(^)

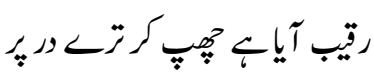

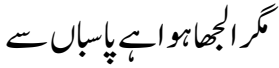

$$
\begin{aligned}
& \text { ايك اوريك لفظى محاوره ملا خط بيدي: }
\end{aligned}
$$

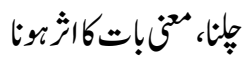

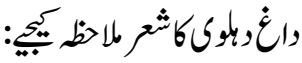

(9)

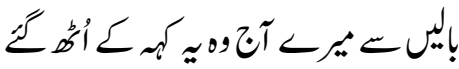

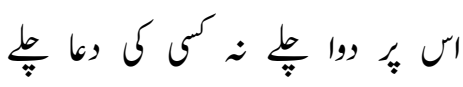

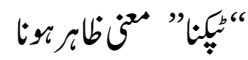


(1•)

$$
\begin{aligned}
& \text { فالبكاثبر لالطي بكي: }
\end{aligned}
$$

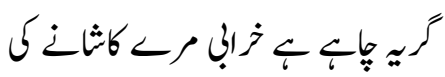

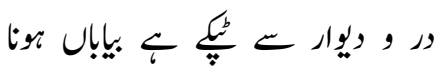

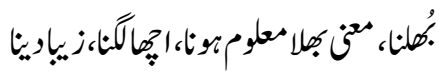

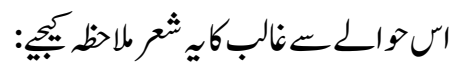

(11)

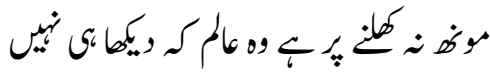

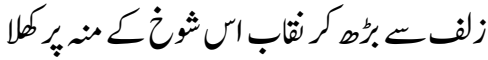

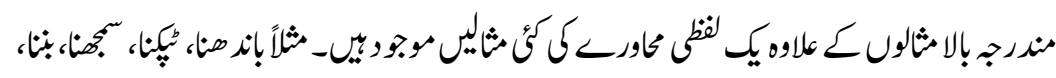

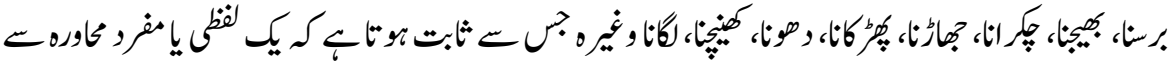

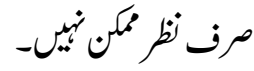

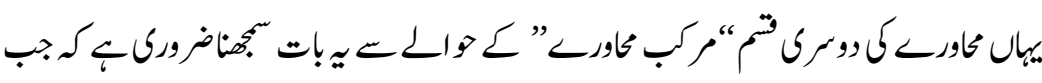

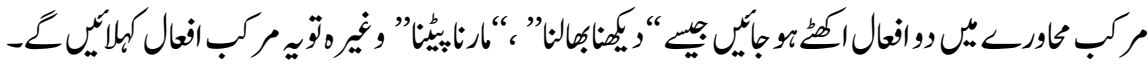

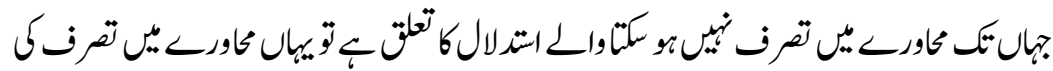

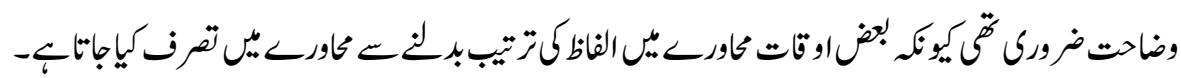

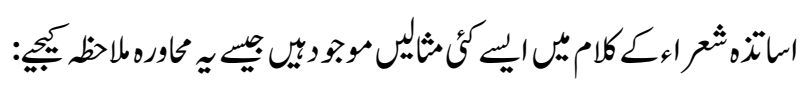

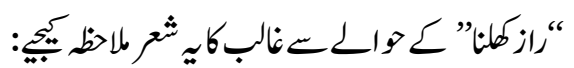

(ir)

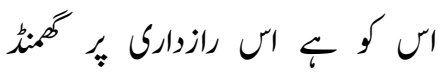

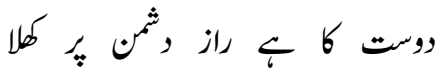

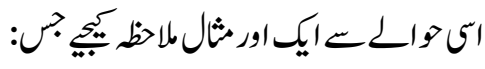

$$
\begin{aligned}
& \text { "اران نكا" }
\end{aligned}
$$




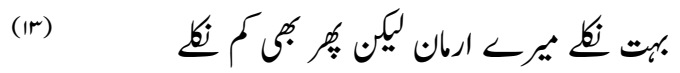

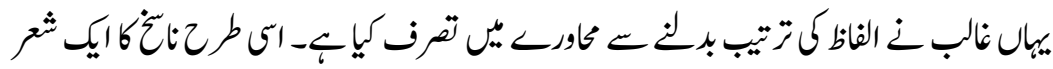

$$
\begin{aligned}
& \text { ملإئي } \\
& \text { “" بميال'ُرانا" }
\end{aligned}
$$

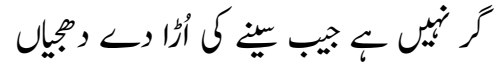

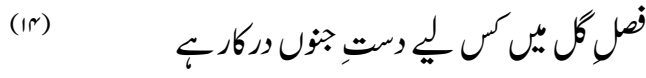

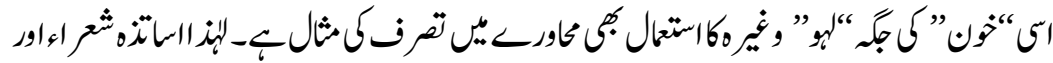

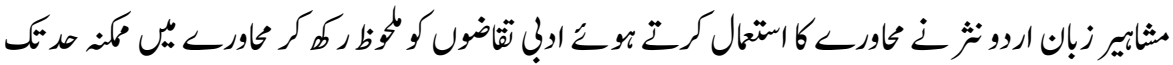

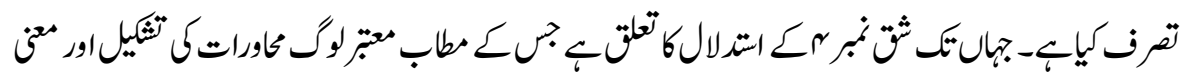

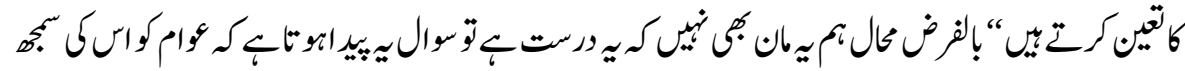

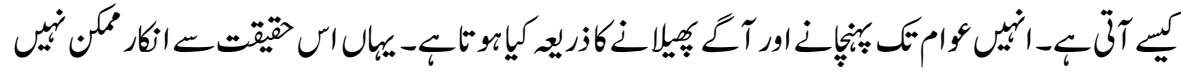

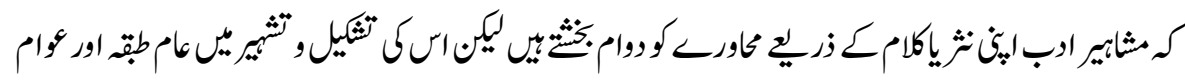

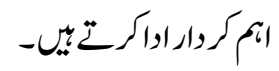

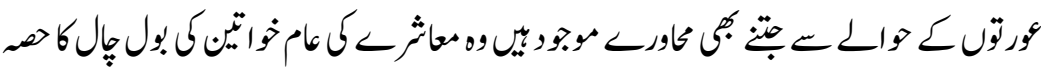

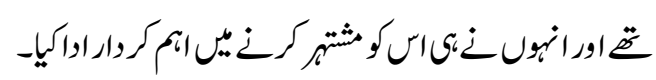

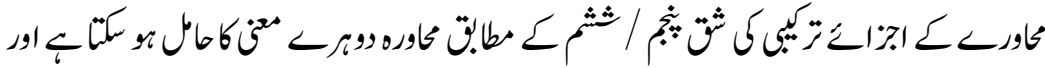

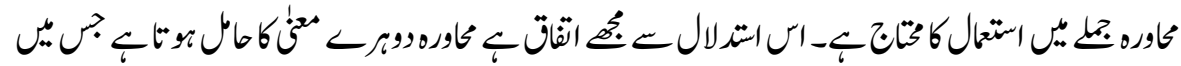

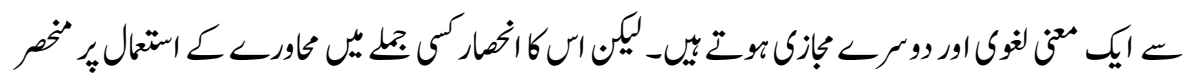




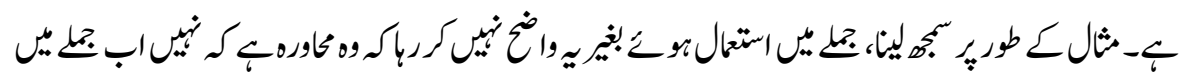

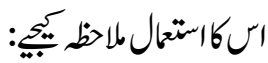

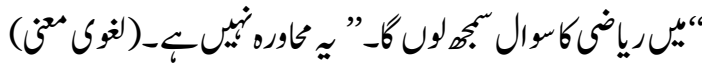

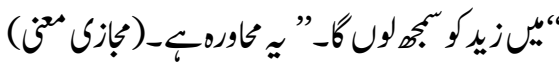

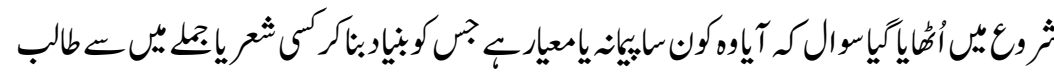

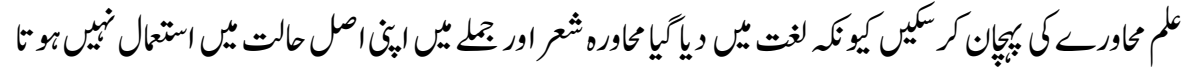

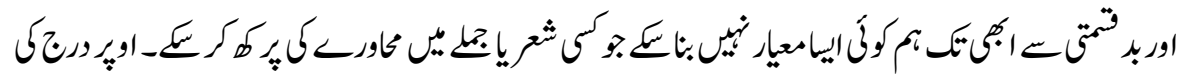

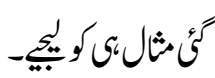

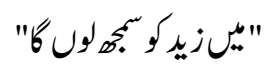

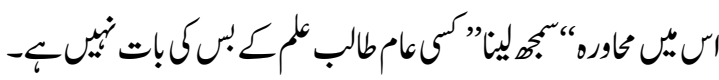$$
\text { واله }
$$

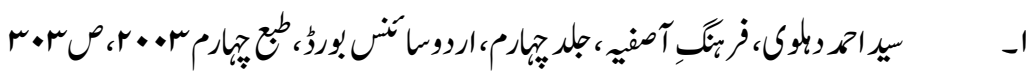

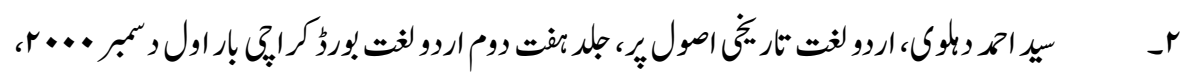

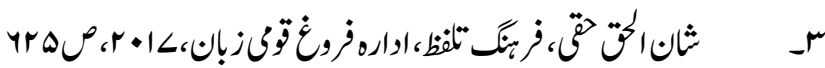

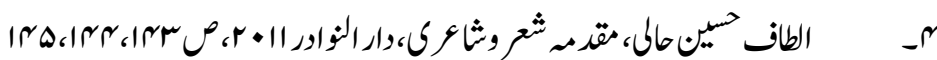

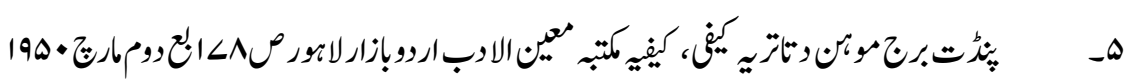

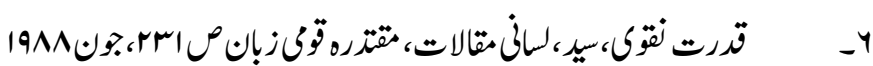
4- - مايناً

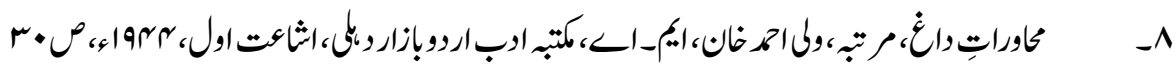

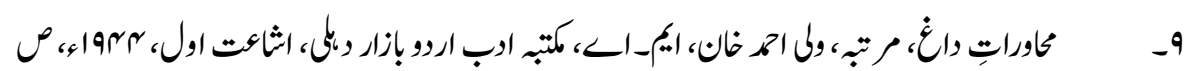




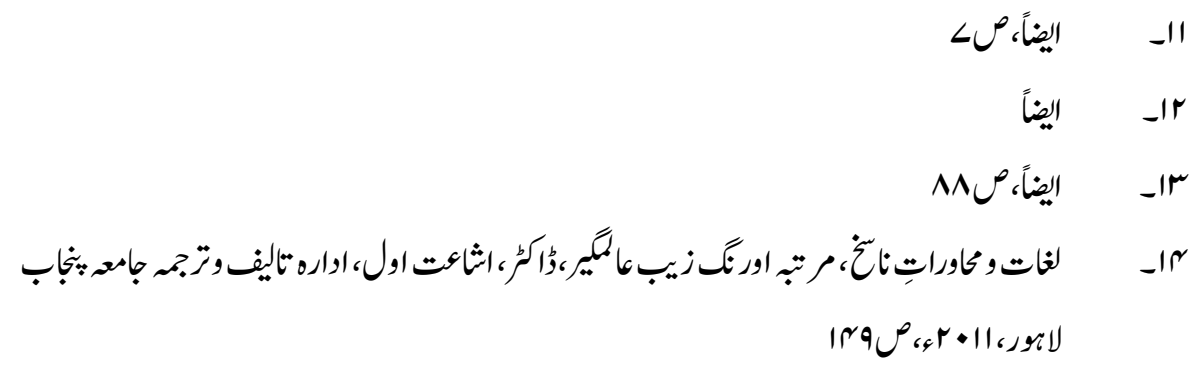

